\section{Debate actual sobre el imperialismo Oscar Mañán}

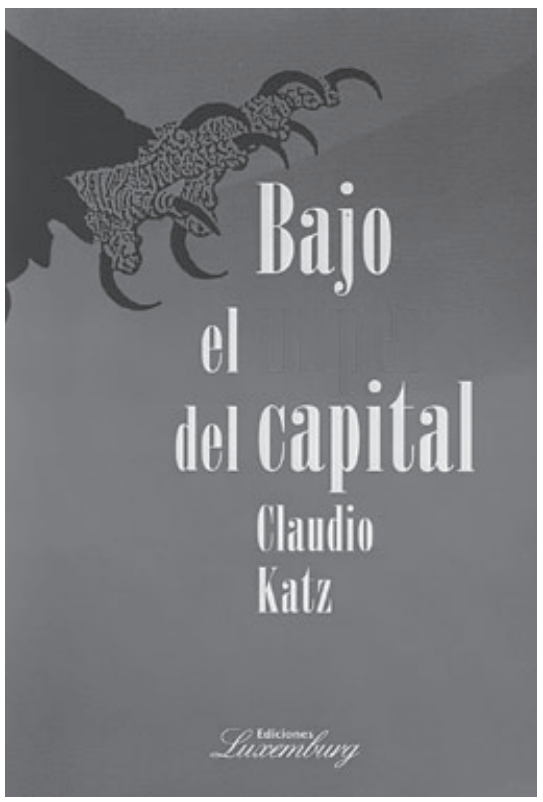

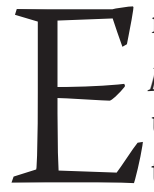

n Bajo el imperio del capital, Claudio Katz aporta un aggiornamiento de la teoría del imperialismo que parte de los clásicos (Kautzky, Lenin, Hilferding y Luxemburgo) hasta arribar a los contemporáneos que buscan dar cuenta de la geopolítica del capital. El libro denuncia la actualidad del imperialismo y la consecuente afectación a la dinámica de los países subdesarrollados; representa una invitación a rescatar los viejos conceptos de la teoría social para crear una nueva perspectiva teórica y revolucionaria. Los primeros capítulos parten de la discusión clásica sobre el imperialismo a partir de Lenin y Kautsky, uno exponente de la propuesta más revolucionaria de superación del capitalismo y el otro de la vertiente socialdemócrata. Ambos coincidían en el papel de la inversión externa: Lenin sostenía la primacía de las finanzas y los monopolios, mientras que Kautsky destacaba el papel de los capitales sobrantes que no encontraban salida a la valorización. Luxemburgo, en cambio, lo veía como salida de mercancías también sobrantes. La teoría marxista surge en épocas de guerras y apropiación del motín colonial y de fuerte rechazo de los revolucionarios a las guerras.

El autor hace una gran recopilación crítica de las teorías marxistas de posguerra, del «capitalismo tardío», «capitalismo de Estado» y «capitalismo monopolista de Estado». El periodo de posguerra creó un marco de estabilidad en torno a nuevos equilibrios geopolíticos. Katz sostiene que «una interpretación actual debe registrar el impacto de la mundialización neoliberal, que ha expandido el radio de acción imperial a todo el planeta, reforzado el papel militar dominante de Estados Unidos» (página 48). ${ }^{1}$ Analiza el papel de Estados Unidos, cuya superioridad militar le permite ejercer como gendarme de las clases dominantes. Este país ha internacionalizado su actividad y usufructúa una ideología compartida por varios sectores capitalistas en el mundo. Los límites están en la desconexión entre el poderío militar y el menguado poder económico y deteriorada solvencia en el plano geopolítico.

Katz revisa los cambios recientes en el capitalismo neoliberal: expansión y movilidad ilimitada de capitales y la crisis que puede cambiar para siempre la realidad de algunos países (i.e., los europeos). También examina el supuesto declive de Estados Unidos, el papel del «nuevo imperialismo» y la contradicción entre la concentración de 
capitales y su dispersión geográfica. La tesis del «imperialismo colectivo» es revisada y se muestra un imperialismo contemporáneo que incluye la dimensión económica, la asociación política y la coerción militar que operan conjuntamente. Aparecen formas de administración de la dominación que sustituye de alguna manera las guerras interimperialistas, combinando - como señala el autor - incursiones conjuntas y agresiones específicas de cada potencia.

Nuevas potencias capitalistas emergen, como Rusia y China, que buscan integrarse y salir al paso de posibles aliados y adversarios de la gestión imperialista. ¿Hay oposición o lucha por la hegemonía entre la expansión de China y el papel imperialista de Estados Unidos? El autor analiza la expansión de China en el marco de la institucionalidad imperialista estadounidense. No existe, hoy por hoy, contraposición entre estas dos economías con fuerte vocación (necesidad) expansionista. Sostiene que China es la única potencia que pasó a ser un país central en la etapa del neoliberalismo, además no considera a esta potencia con una clase dominante que tenga aspiraciones imperialistas; sin embargo, ahora deberá jugar en las ligas mayores y las obligaciones cambian. Quizá la anterior afirmación esté influida por lo que significa la crisis que afecta a buena parte del mundo capitalista. En tiempos de crisis es posible esperar que la «clase general» se compacte, articule acciones, pero ¿esto habla de un «nuevo» imperialismo corporativo? La historia dirá si será o no posible un recrudecimiento de las luchas interimperialistas con una nueva etapa de auge. De todos modos, deja planteado un conjunto de tensiones existentes en la corporación imperialista (Estados Unidos-Europa-Japón) y manifiesta algunas preguntas sobre el papel de la semiperiferia, los BRICS en particular (Brasil, Rusia, India, China y Sudáfrica), y la incorporación de África y América Latina en estos conflictos.

Uno de los temas que rescata es la autonomía relativa del Estado: cómo genera las condiciones de reproducción del capital. En el caso de los países de la región, existen Estados donde los gestores, la «alta burocracia» se define progresista o de izquierda, pero no se aparta del papel que exige la institucionalidad que rige el capitalismo mundial. Otro de los temas que soslaya y abre eventualmente al análisis - crucial para la región- es el vínculo de esa «alta burocracia» con las clases dominantes. Justamente, en el último capítulo habla de conceptos para vincular y desarrollar, la ideología, el Estado y las clases sociales.

NOTA

1 Claudio Katz, Bajo el imperio del capital, Buenos Aires, Ediciones Luxemburg, 2011, p. 48. 